Sharif University of Technology
Scientia Iranica
SCIENTIA

\title{
Roughness and turbulence effects on the aerodynamic efficiency of a wind turbine blade section
}

\author{
M.R. Soltani ${ }^{a, *}$, F. Askari ${ }^{a}$ and V. Sadri ${ }^{b}$ \\ a. Department of Aerospace Engineering, Sharif University of Technology, Tehran, P.O. Box 11155-8, Iran. \\ b. Department of Mechanical Engineering Lyle School of Engineering, Southern Methodist University, P.O. Box 750337 Dallas, TX \\ 75275, USA.
}

Received 2 March 2012; received in revised form 15 March 2015; accepted 16 June 2015

\section{KEYWORDS}

Wind turbine;

Airfoil characteristics;

Roughness sensitivity;

Pitching;

Plunging;

Wind tunnel.

\begin{abstract}
Numerous experiments were conducted on the section of a $660 \mathrm{kw}$ wind turbine blade in a subsonic wind tunnel. The selected airfoil was tested with a clean and distributed contamination roughness surface, with a high and low tunnel turbulence intensity. Surface contamination was simulated by applying $0.5 \mathrm{~mm}$ height roughness over the entire upper surface of the airfoil. The surface pressure distribution is measured under a steady and unsteady condition, at three Reynolds numbers; 0.43 , 0.85, and 1.3 million, and over a range of angles of attack, $\mathrm{AOA}=7^{\circ}-19^{\circ}$. Unsteady data were acquired by both pitch and plunge-type oscillation of the model about its quarter chord at a reduced frequency of 0.07 . Results show that the surface roughness reduces section aerodynamic efficiency and the lift coefficient, but increases the drag coefficient for all Reynolds numbers. The application of roughness reduces the upper surface pressure coefficient and extends a separation region at high angles of attack. Increasing the tunnel turbulence intensity resulted in delay of the stall, an increase of maximum lift coefficient, and smoothness of stall behavior. However, the drag coefficient increased significantly. Furthermore, turbulence intensity affected the predicted power output of the blade.
\end{abstract}

(C) 2016 Sharif University of Technology. All rights reserved.

\section{Introduction}

Wind energy has attracted a great deal of attention in recent years as one of the more promising alternative renewable energy resources. Wind is a free, clean, and inexhaustible energy source. Generating electricity from the wind is a mature technology, and economically competitive for most fossil fuel applications. Turbine blades take advantage of aerodynamics to extract wind energy, which can then be converted to useful electricity. Airfoils determine the aerodynamic forces on the blades. The design and performance assessment of wind turbines is presently performed by means of blade element theories. These theories are based on two

\footnotetext{
*. Corresponding author.

E-mail address: msoltani@sharif.edu (M.R. Soltani)
}

dimensional lift and drag characteristics that clearly indicate the importance of acquiring accurate airfoil data. Moreover, during the design process, it is critical to be able to correctly predict the aerodynamic behavior of airfoils under different conditions. Inaccurate prediction of wind turbine power and structural load leads to insufficient design of its components, and can cause premature failure.

Under natural conditions, bugs and dirt often contaminate wind turbine blades at their leading edges. Leading edge roughness increases the thickness of the boundary layer and moves the transition point forward. Therefore, the thicker turbulent boundary layer causes drag rise, which reduces the effective camber and may cause premature stall. In summary, it can be said that roughness has an undesirable effect on aerodynamic efficiency and its amount depends on the philosophy 
of airfoil design and the degree of pollution on the blade surface [1-3]. Little work has been done on the effect of turbulence on the performance of an airfoil section when operating near its stall condition, and some results are still contradictory $[4,5]$.

All aerodynamic objects (except military aircraft) avoid stall as much as possible because of the associated high loads and the possible loss of aerodynamic damping. However, many wind turbines operate near stall, both statically and dynamically, and, thus, a comprehensive understanding of unsteady stall is necessary. Stall phenomena can reduce output power on the pitchcontrolled wind turbines when encountering turbulent flow. Generally, this phenomenon is sensitive to various parameters, such as surface roughness, Turbulent Intensity (TI), fluid motion type, Reynolds number, and imperfections of the sectional airfoil contour. There is a good body of work on investigating the effects of these parameters on the aerodynamic performance of the vehicle in [6-8]. Flow with high TI may decrease output power and can cause extreme loading on the wind turbine components. Therefore, turbulence levels are an important characteristic of oncoming wind. Installing a wind tower near obstructions such as trees or buildings can alter the magnitude of the site's overall wind resources to output electricity, by the increase in wind shear and turbulence levels. Wind turbulence is rapid disturbances or irregularities in the wind speed, direction, and its vertical component. Standard deviations of wind speed and wind direction are indicators of wind turbulence and atmospheric stability.

Hojstrup [9] and Hogstrom et al. [10] carried out a field experiment and found that turbulence effects are noticeable, even at 10D-12D (diameters) downstream of installed wind turbines, respectively, whereas velocity defects are almost negligible at those distances. Consequently, it is proposed that turbulence effects are more persistent, and the decay of the velocity deficit is faster than the decay of turbulence intensity. Turbulence intensity decreases with downstream distance, and increases with the thrust coefficient. In general, the turbulence in the wake seems to be more isotropic than in the outside flow, although, there are some local turbulence intensity peaks in the wind direction components that are less intense for turbulence intensities in the other directions. These peaks occur where the gradient of the average velocity is the largest.

One reason for under-predicting the aerodynamic performance of a wind turbine has been attributed to its dynamic stall. McCroskey [11] presents an excellent review of this phenomenon. All wind turbines operate with some parts of the blade stalled for a portion of time. Prior to 1991, dynamic stall and unsteady aerodynamic effects were not included in the HAWT performance and load analysis. The first model implemented in aeroelastic codes to investigate dynamic stall on wind turbines was created by Oye [12]. In 1993, Hansen and Butterfield [13] were able to quantify both the existence of dynamic stall and its effect on rotor loads by measuring surface pressure distributions on a $10 \mathrm{~m}$ HAWT.

Load and performance calculations of wind turbines are, today, routinely performed by the BladeElement/Momentum (BEM) method [14]. When using this method, efficiency characteristics of the blade sections should be provided through experimental tests. Previous works show that the results depend on the conditions of the tests. Differences between the results of various experiments are mainly due to ignoring the effects of some parameters, such as roughness, turbulence intensity, dynamic stall, etc. all of which will cause inaccurate prediction of the aerodynamic behavior of the blade section under study.

During the process of design of a $660 \mathrm{kw}$ wind turbine blade, effects of the free stream TI on the aerodynamic loads of a critical section of its blade have been experimentally investigated. No experimental or theoretical data on the aerodynamic characteristics of the airfoil section used in the blades of this turbine were available at the time of this investigation. In addition, the effects of TI on the predicted output power of the blade were examined using a computer program developed based on the BEM method.

\section{Experimental facility}

All experiments were conducted in a low-speed wind tunnel. It is a closed circuit tunnel with a rectangular test section of $0.80 \times 0.80 \times 2.00 \mathrm{~m}$, and a total dimension of $3.8 \times 6.5 \times 18 \mathrm{~m}^{3}$. The test section speed varies continuously from 10 to $100 \mathrm{~m} / \mathrm{s}$. Experimental tests were carried out at a range of Re numbers, from $0.43 \times 10^{6}$ to $0.85 \times 10^{6}$, for both high and low TI. Roughness numbers of 16 and 36 were mounted on the airfoil surface. The average particle diameter for grit numbers of 16 and 36 is 1092 and $483 \mu \mathrm{m}$, respectively. According to the roughness pattern (Figure 2), the grits were distributed on the $1.2 \mathrm{~cm}$ width double sided adhesive tape, and the center of the tape was mounted at $x / c=0.05$ on the suction side of the model.

Comparison of the tunnel turbulence level with other wind tunnels showed that the turbulence level in this tunnel is slightly higher than the standard values. This wind tunnel was at first equipped with one screen, and, hence, its turbulence intensity at the test section was relatively high. For turbulence reduction in this wind tunnel, three more screens were mounted in its contraction region. Measurements showed that these screens reduced turbulence intensity at the test section to within the standard range at different Reynolds 


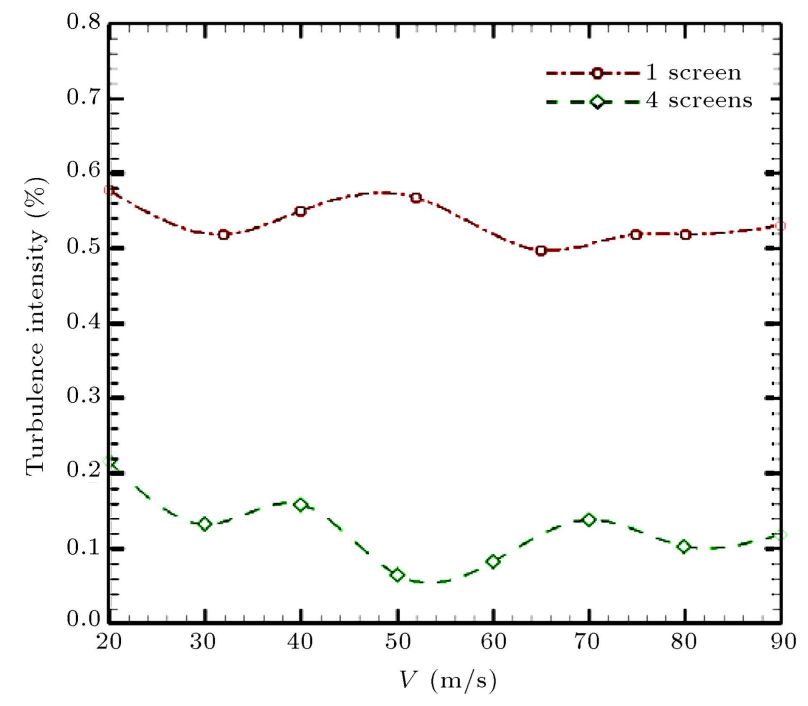

Figure 1. Effect of screens on turbulence intensity of test section.

Table 1. Turbulence intensity in the test section in $\%$.

\begin{tabular}{lccc}
\hline Reynolds number & $\mathbf{4 3 0 , 0 0 0}$ & $\mathbf{8 5 0 , 0 0 0}$ & $\mathbf{1 , 3 0 0 , 0 0 0}$ \\
\hline Without grid & $0.1328 \%$ & $0.08504 \%$ & $0.1175 \%$ \\
With grid & $0.4225 \%$ & $0.5396 \%$ & - \\
\hline
\end{tabular}

number. Figure 1 shows effect of inserting screens in the contraction region of the tunnel on turbulence intensity. Further, the test section turbulence was varied by placing a grid in front of the test section. Use of the grid in the tunnel reduced the maximum velocity in the test section; hence, study of the turbulence effect at a Reynolds no. of $1.3 \times 10^{6}$ was not possible. The turbulence intensity in the test section for specified Reynolds numbers, with and without grids, is shown in Table 1, and was measured by hot wire inserted into the test section.

The model in the present study has a $0.25 \mathrm{~m}$ chord and $0.80 \mathrm{~m}$ span, and is a section of a $660 \mathrm{~kW}$ wind turbine blade. Table 2 shows the dimensionless coordinates of the airfoil used in this investigation. The airfoil is equipped with 64 pressure orifices on its upper and lower surfaces. The pressure ports are located along the chord at an angle of 20 degrees, with respect to the airfoil span, to minimize disturbances from the upstream taps (Figure 2). Data was obtained using sensitive pressure transducers. Due to the high number of pressure ports and the size of the selected pressure transducers, it was not possible to place the transducers inside the model. Therefore, extensive experiments were conducted to ensure that the frequency response of the pressure-measuring system was kept well above the highest oscillation frequency. Finally, the tube length and the material that gave the minimum time lag for all applied pressures were selected. For the selected tubes, the maximum amount of time lag was less
Table 2. Airfoil coordinates.

\begin{tabular}{|c|c|c|c|}
\hline \multicolumn{2}{|c|}{ Upper surface } & \multicolumn{2}{|c|}{ Lower surface } \\
\hline$X / C$ & $Y / C$ & $X / C$ & $Y / C$ \\
\hline 0 & 0 & 0.002536 & -0.00658 \\
\hline 0.000949 & 0.008236 & 0.004715 & -0.00935 \\
\hline 0.002881 & 0.012172 & 0.006895 & -0.01213 \\
\hline 0.004813 & 0.016109 & 0.008635 & -0.01377 \\
\hline 0.007071 & 0.01912 & 0.010376 & -0.01541 \\
\hline 0.00933 & 0.022131 & 0.012193 & -0.01679 \\
\hline 0.011796 & 0.024682 & 0.01401 & -0.01817 \\
\hline 0.014262 & 0.027232 & 0.016901 & -0.01994 \\
\hline 0.017223 & 0.029809 & 0.019792 & -0.02171 \\
\hline 0.020184 & 0.032386 & 0.026016 & -0.02481 \\
\hline 0.023256 & 0.034713 & 0.032149 & -0.02723 \\
\hline 0.026328 & 0.037039 & 0.038282 & -0.02965 \\
\hline 0.032277 & 0.040979 & 0.051398 & -0.03371 \\
\hline 0.038226 & 0.044918 & 0.079198 & -0.0406 \\
\hline 0.051266 & 0.052348 & 0.10894 & -0.04631 \\
\hline 0.078726 & 0.06529 & 0.151872 & -0.05227 \\
\hline 0.108641 & 0.076686 & 0.195398 & -0.05626 \\
\hline 0.151377 & 0.089529 & 0.247808 & -0.05918 \\
\hline 0.195189 & 0.09943 & 0.29987 & -0.06023 \\
\hline 0.24758 & 0.107957 & 0.35077 & -0.05942 \\
\hline 0.299925 & 0.113383 & 0.400896 & -0.05682 \\
\hline 0.350759 & 0.115853 & 0.450927 & -0.05257 \\
\hline 0.400936 & 0.1156 & 0.500861 & -0.04702 \\
\hline 0.500902 & 0.10788 & 0.550863 & -0.0405 \\
\hline 0.550973 & 0.101074 & 0.600801 & -0.03335 \\
\hline 0.600847 & 0.092695 & 0.650768 & -0.02588 \\
\hline 0.650921 & 0.082898 & 0.700727 & -0.01839 \\
\hline 0.700807 & 0.072026 & 0.750619 & -0.01123 \\
\hline 0.750842 & 0.060277 & 0.800577 & -0.00487 \\
\hline 0.800742 & 0.04794 & 0.850538 & 0.00016 \\
\hline 0.850656 & 0.035254 & 0.002536 & -0.00658 \\
\hline 0.900622 & 0.003292 & 0.004715 & -0.00935 \\
\hline 0.950657 & 0.010813 & & \\
\hline 1 & 0 & & \\
\hline
\end{tabular}

than $10 \mathrm{~ms}$. This means that the frequency response at the end of the tubes, including the transducer's volume, viscosity and all other factors, was greater than $100 \mathrm{~Hz}$. In the static tests, to measure the total pressure loss in the wake region, a rake was designed and manufactured, as seen in Figure 3. The rake had 67 total pressure ports and 5 static ones. The vertical span of the rake was $0.3 \mathrm{~m}$, and the distances between the probes of the rake varied from $3 \mathrm{~mm}$ at the center, to $10 \mathrm{~mm}$ at the sides. The rake was located at 1.2 

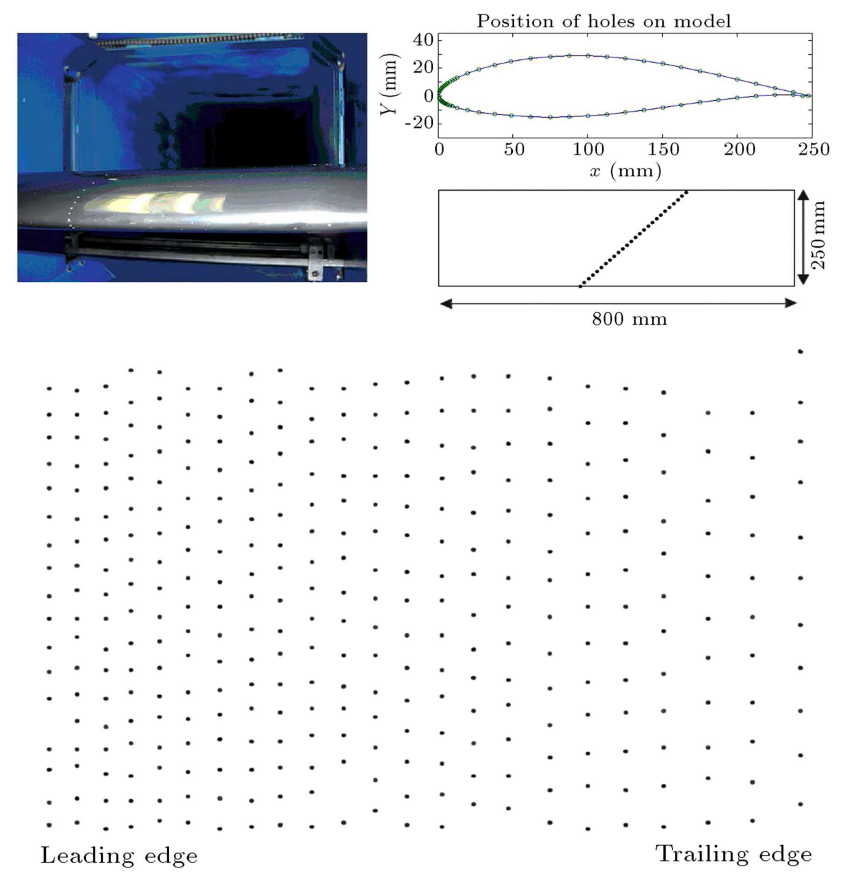

Figure 2. Airfoil model and the location of the pressure ports.

airfoil chords behind the airfoil, and the related total profile drag at all angles of attack was calculated from the measured total and static pressures.

Figure 3 shows the oscillating mechanism used in this investigation. The oscillation system for the pitching motion uses a crankshaft to convert the circular motion of the motor to a reciprocal motion, which is then transferred to the model by means of a rod. The pitch rotation point is fixed about the wing quarter chord. The model angle of attack was varied sinusoidally as $\alpha=\alpha_{0}+\sin \omega t$. The present systems can oscillate the model at various amplitudes, mean angles of attack, and frequencies ranging from 1 to $4 \mathrm{~Hz}$.

All static data was corrected for the solid tunnel sidewalls and the wake blockage effects using the method explained by Barlow et al. [15]. Acquired oscillatory data were digitally filtered using a low pass filter with various cut-off and transition frequencies to find the best frequencies to fit the original data [16]. For each unsteady flow case, several repeated cycles were performed for ensemble averaging. Finally, all oscillatory data were corrected for the solid tunnel sidewalls and the wake blockage effects [16].

Before a data set can be used in an engineering or scientific application, its quality must be established. Since this section of the wind turbine was tested for the first time and there are no experiment/numerical data available for comparison, an error analysis was performed to validate the acquired data. Using the method explained by Carta [16], both the single sample precision and the bias uncertainty in each measured

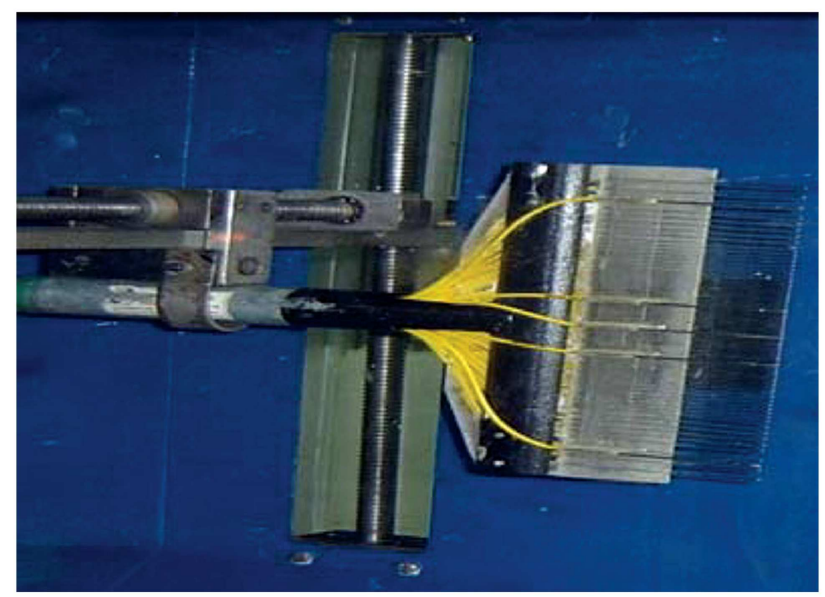

(a)

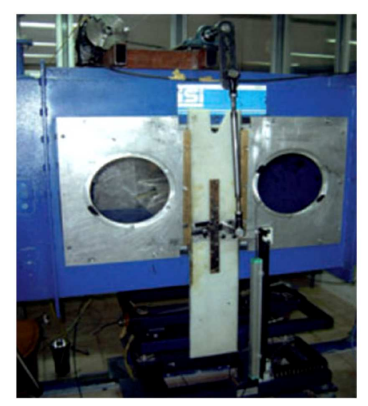

(b)

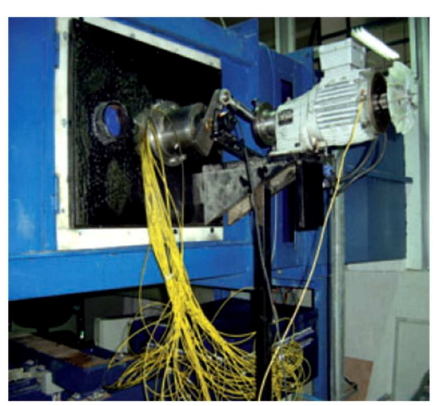

(c)
Figure 3. (a) Rake and traversing system. (b) Plunging oscillation system. (c) Pitching oscillation system.

variable were estimated, and then were propagated into the $C_{P}$ variations. The maximum overall uncertainty calculated in this way for the $C_{P}$ data was less than $\pm 1.9 \%$ of the total measured $C_{P}$ values.

\section{Results and discussion}

Experimental wind tunnel tests are conducted for a critical section of a $660 \mathrm{KW}$ wind turbine at various TI's. In addition, a computer code based on the BEM method is developed to predict the output power of the blade using the acquired experimental results. The results will be discussed in three parts:

1. Experimental results for the static condition;

2. Experimental results for the unsteady oscillation condition;

3. Simulation results for the output power predicted by the BEM code.

\subsection{Effects of roughness and TI on the static coefficients}

Effects of roughness on the surface pressure distribution at three Reynolds numbers of $0.43,0.85$, and 1.3 million, and over a range of angles of attack, $\mathrm{AOA}=7^{\circ}-$ $19^{\circ}$, are shown in Figures 4-6. From these figures, it is seen that roughness has changed the pressure 


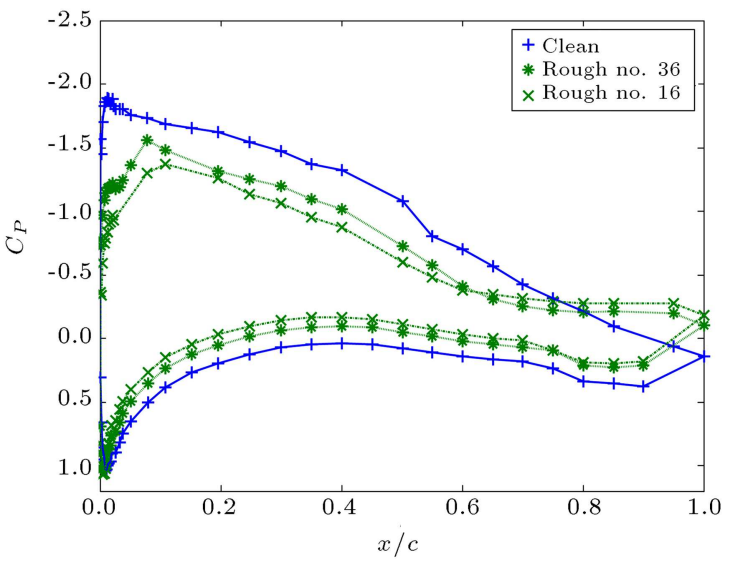

(a) $\mathrm{AOA}=7^{\circ}$

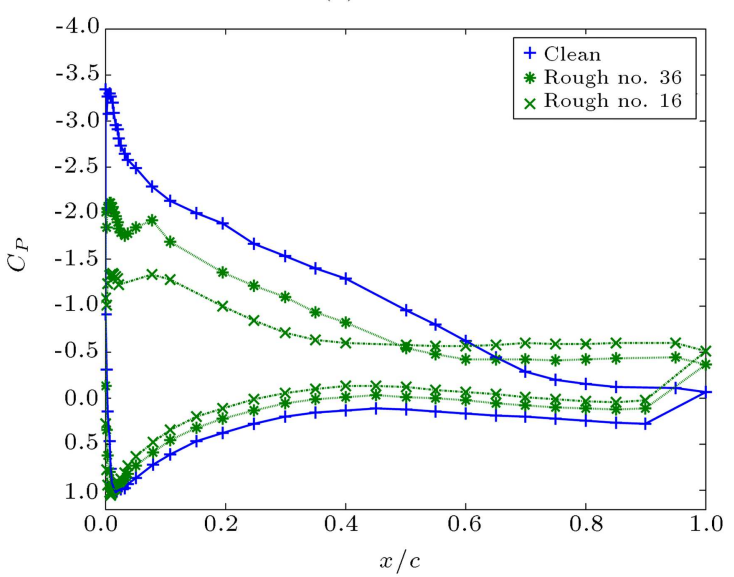

(b) $\mathrm{AOA}=12^{\circ}$

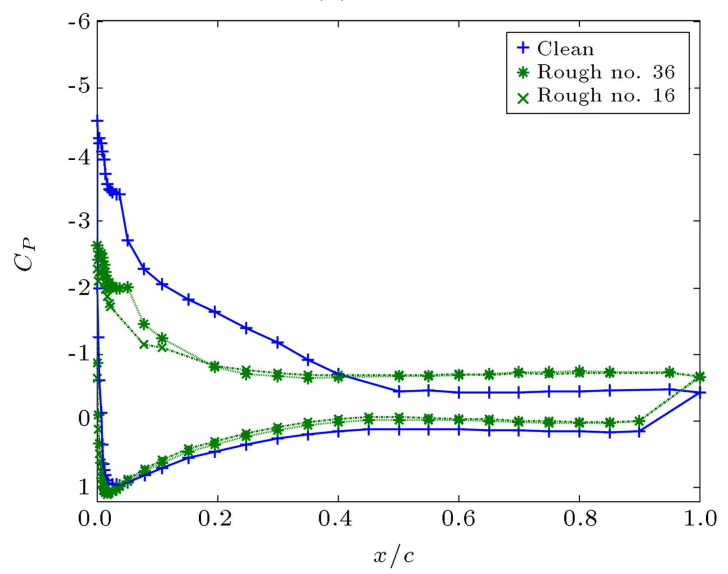

(c) $\mathrm{AOA}=17^{\circ}$

Figure 4. Effect of roughness on the pressure signature at $\operatorname{Re}=0.43 \times 10^{6}$.

distribution for both upper and lower surfaces. Note that the roughness is installed on the upper surface of the model only. As shown in [17], roughness reduces suction peak drastically and extends the separation point towards the leading edge. Figure 4 shows that, as angles of attack increase, flow separation moves towards the leading edge and roughness promotes this. For instance, at a $17^{\circ}$ angle of attack, Figure 4(c) shows that separated flow covers about $50 \%$ of the upper

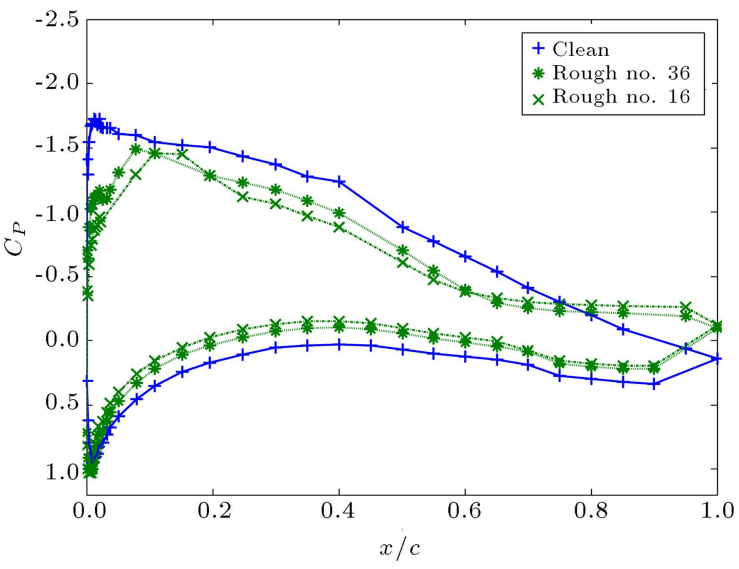

(a) $\mathrm{AOA}=7^{\circ}$

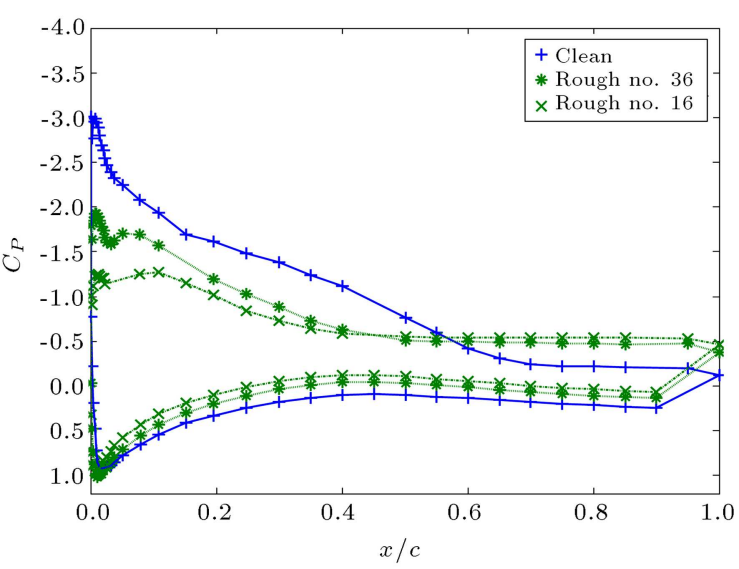

(b) $\mathrm{AOA}=12^{\circ}$

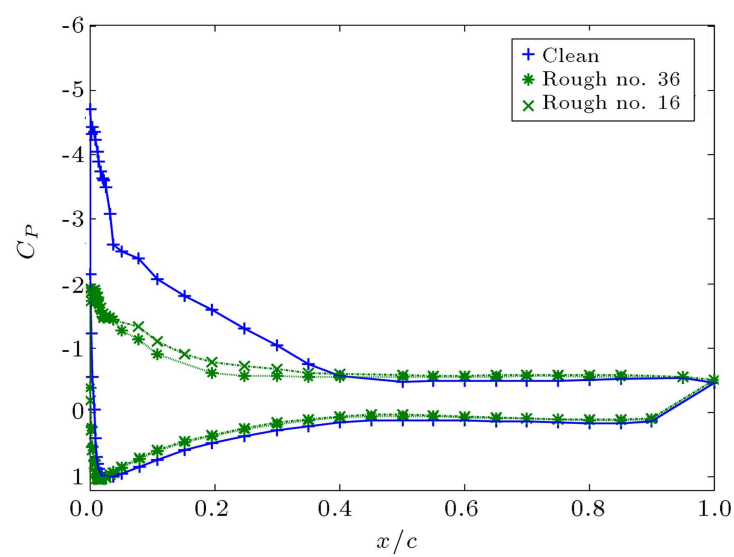

(c) $\mathrm{AOA}=17^{\circ}$

Figure 5. Effect of roughness on the pressure signature at $\operatorname{Re}=0.85 \times 10^{6}$.

surface of the airfoil in the clean case while roughness enhances this separation to $75 \%$ of the airfoil. Similar cases are seen for other angles of attacks and other Reynolds numbers. These variations are clearly seen in Figure 7, where the percent of separation over the airfoil surface is plotted versus angles of attack for the aforementioned Reynolds numbers and two different roughness sizes. Note that the percent of separation is obtained from Figures 4-6. These figures 


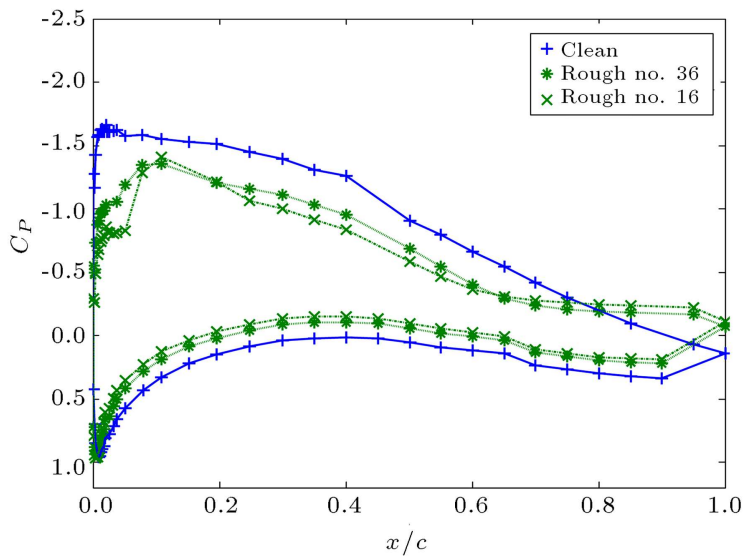

(a) $\mathrm{AOA}=7^{\circ}$

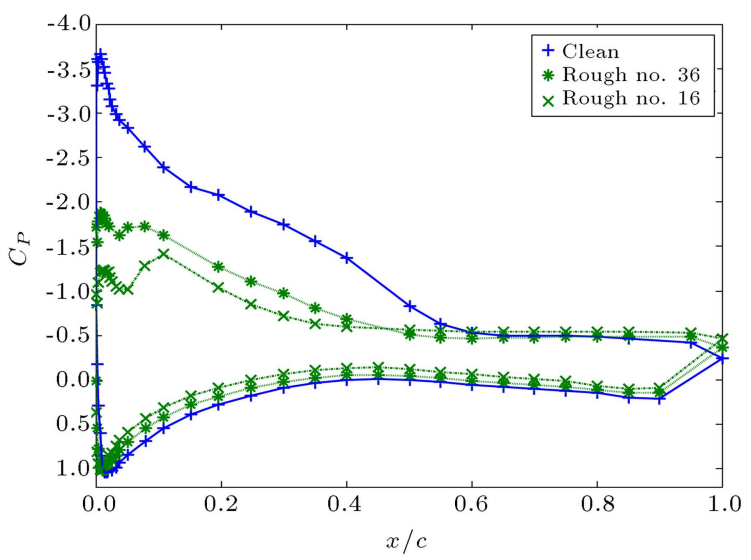

(b) $\mathrm{AOA}=12^{\circ}$

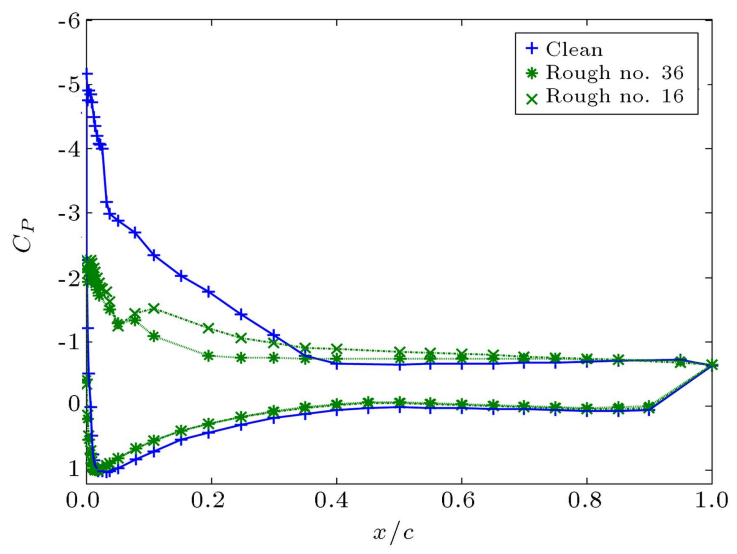

(c) $\mathrm{AOA}=17^{\circ}$

Figure 6. Effect of roughness on the pressure signature at $\operatorname{Re}=1.3 \times 10^{6}$.

clearly show both the effect of Reynolds number and surface roughness on the separation point over the airfoil as the angle of attack is varied. Moreover, as roughness decreases suction peak, drastically, the minimum pressure for all angles of attack and Reynolds number is tested here. However, at low angle of attack, the reduction is minimal and becomes more pronounced as the angles of attack increase.

Figure 8 shows the variation of lift coefficient with angle of attack for the clean and rough model

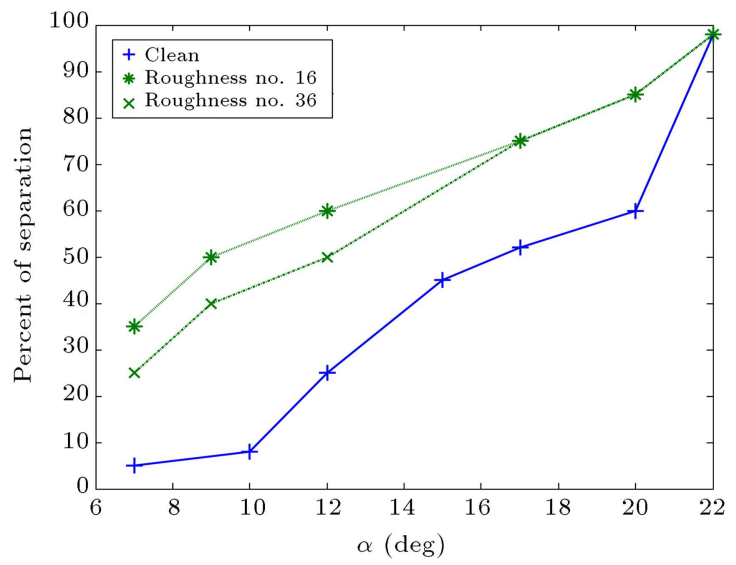

(a) $\operatorname{Re}=0.43 \times 10^{6}$

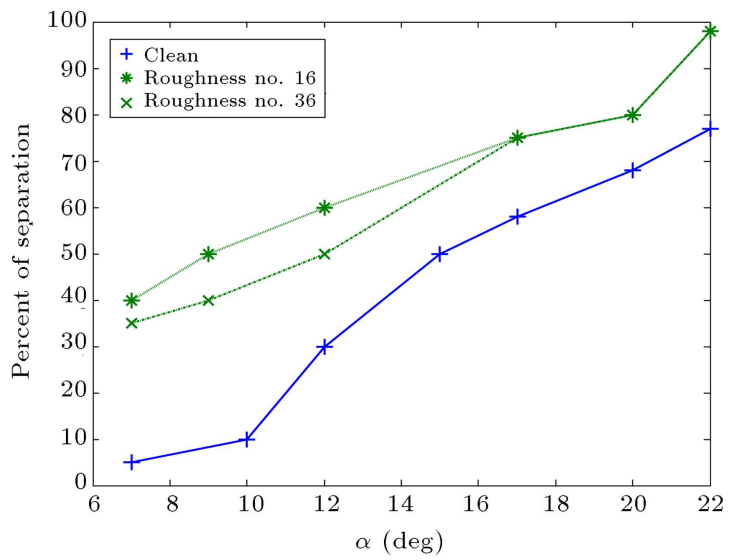

(b) $\operatorname{Re}=0.85 \times 10^{6}$

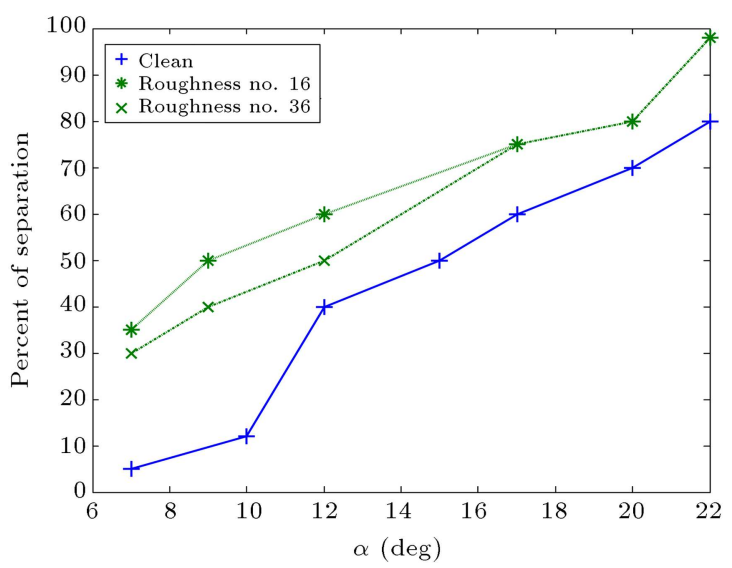

(c) $\operatorname{Re}=1.3 \times 10^{6}$

Figure 7. Effect of roughness on the separation region.

at three different Reynolds numbers: $R e=0.43 \times 10^{6}$, $\operatorname{Re}=0.85 \times 10^{6}$ and $\operatorname{Re}=1.3 \times 10^{6}$. From this figure, it is clearly seen that surface roughness decreases lift values for all angles of attack significantly. Roughness no. 36 reduces maximum lift coefficient about $25 \%$, $27 \%$ and $33 \%$ at the aforementioned Reynolds numbers. In contrast to what is expected, the roughness effect on the lift coefficient is stronger at high Reynolds number. The effect of roughness no. of 16 is greater than roughness no. of 36 . Roughness no. of 36 delays 


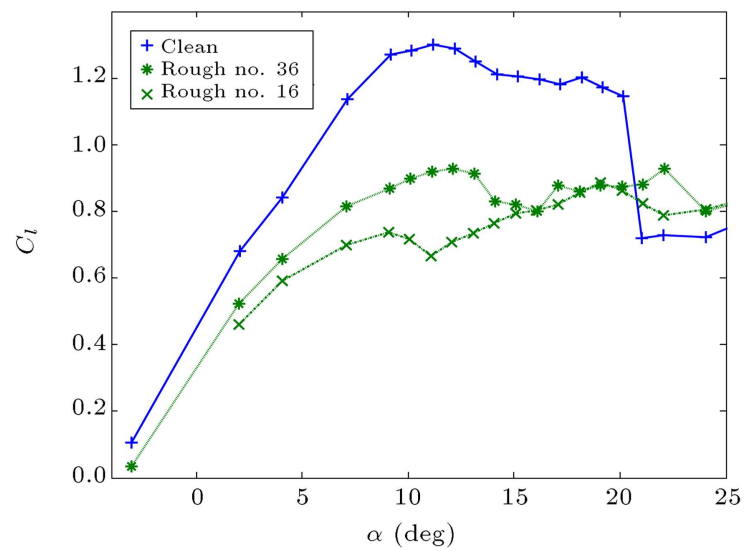

(a) $\operatorname{Re}=0.43 \times 10^{6}$

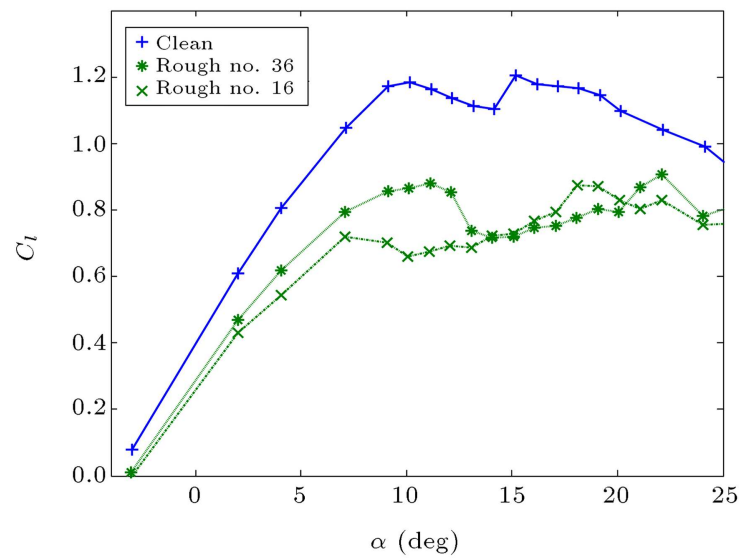

(b) $\operatorname{Re}=0.85 \times 10^{6}$

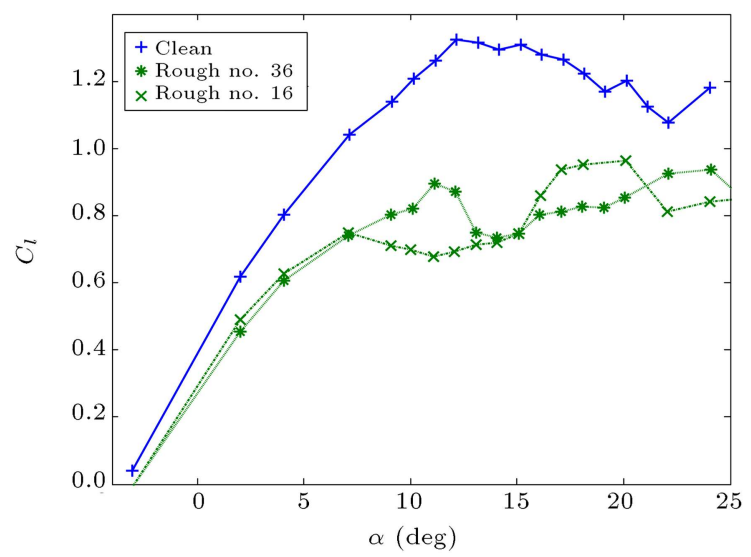

(c) $\operatorname{Re}=1.3 \times 10^{6}$

Figure 8. Effect of leading edge roughness on the lift coefficient.

stall slightly at $\operatorname{Re}=0.43 \times 10^{6}$ and $\operatorname{Re}=0.85 \times 10^{6}$ but roughness no. of 16 promotes stall at all Reynolds numbers tested here.

Figure 9 shows variation of the drag coefficient, $\mathcal{C}_{d}$, with angle of attack for the clean and rough model at three aforementioned Reynolds numbers obtained by the surface pressure data. Roughness increases drag coefficient considerably. These variations are strongly affected by the type of roughness; i.e. roughness no.

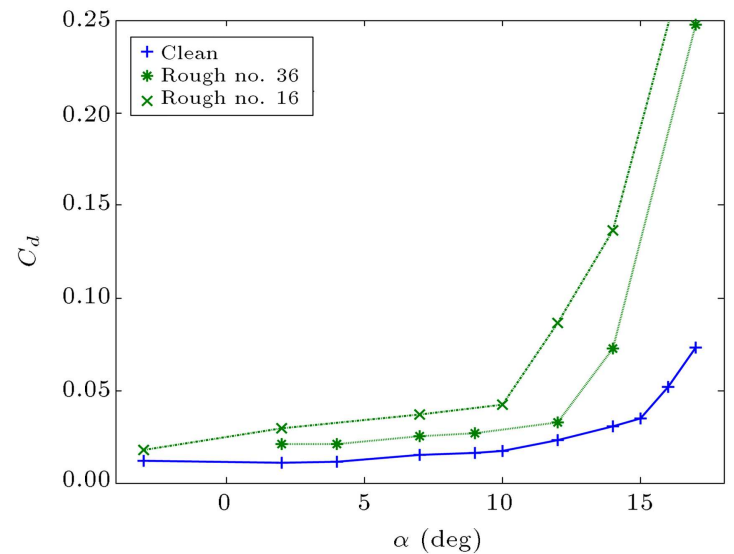

(a) $\operatorname{Re}=0.43 \times 10^{6}$

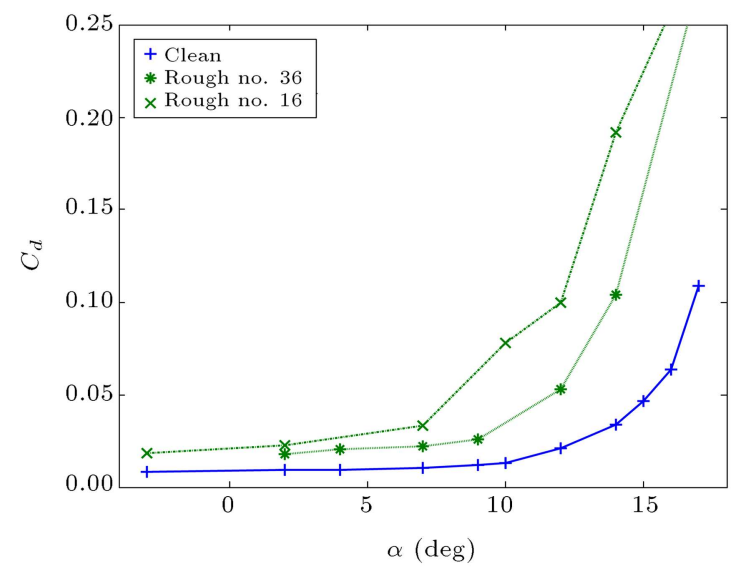

(b) $\operatorname{Re}=0.85 \times 10^{6}$

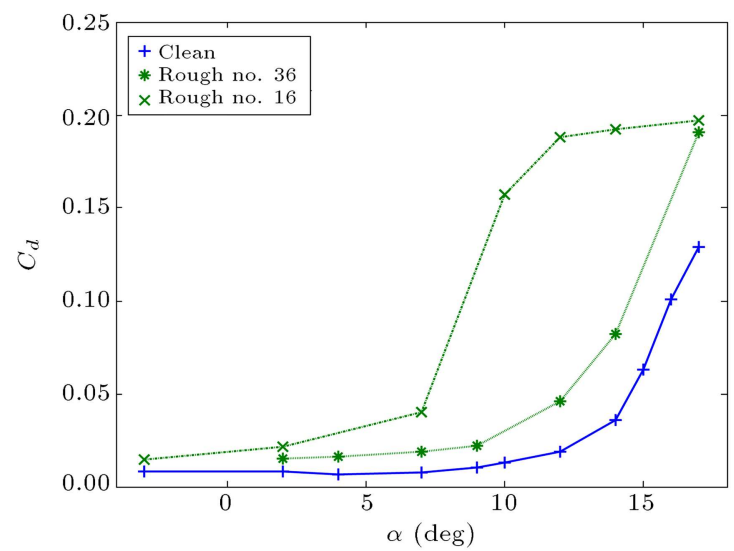

(c) $\operatorname{Re}=1.3 \times 10^{6}$

Figure 9. Effect of leading edge roughness on the drag coefficient.

16 causes maximum variations. Minimum $\mathcal{C}_{d}$ is higher about $40 \%$ for roughness no. of 36 , and $50 \%$ for roughness no. of 16 , in comparison with the clean model at the same Reynolds number of $\operatorname{Re}=0.85 \times 10^{6}$. Roughness also causes earlier drag rise, as seen from Figure 9. For both cases examined here, however, that of no. 36 occurs at a smaller angle of attack.

Figure 10 shows the effect of roughness on the $\frac{\mathcal{C}_{l}}{\mathcal{C}_{d}}$ curve for different Reynolds numbers. It is seen by 


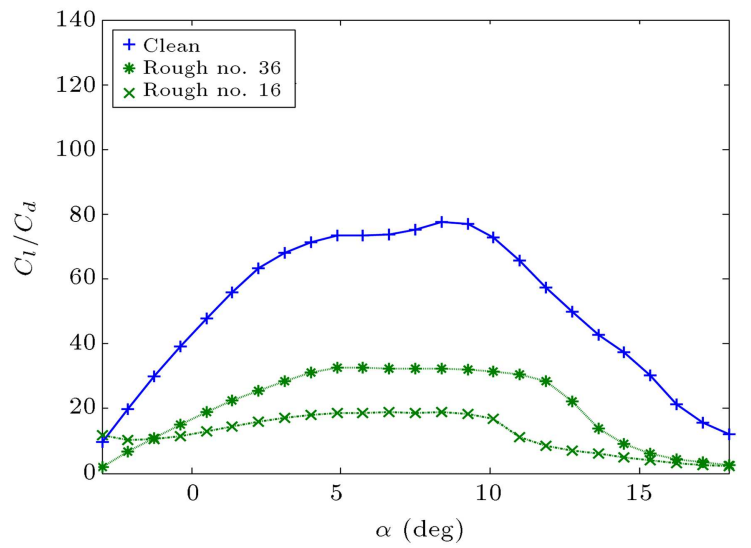

(a) $\operatorname{Re}=0.43 \times 10^{6}$

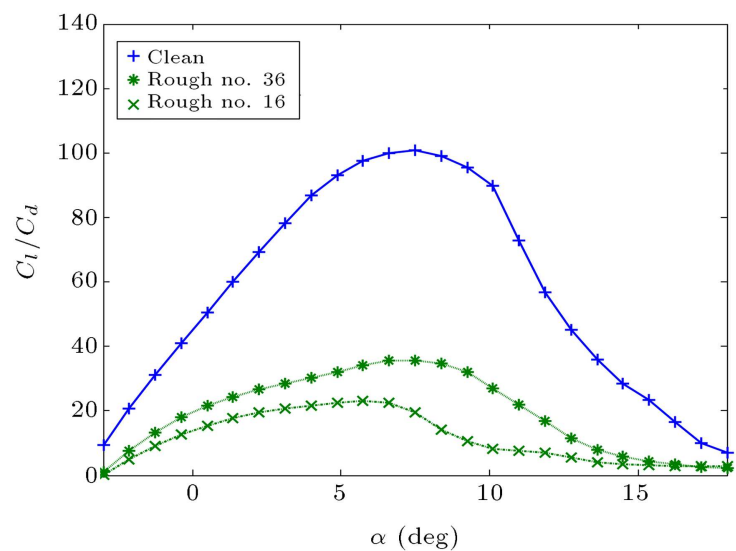

(b) $\operatorname{Re}=0.85 \times 10^{6}$

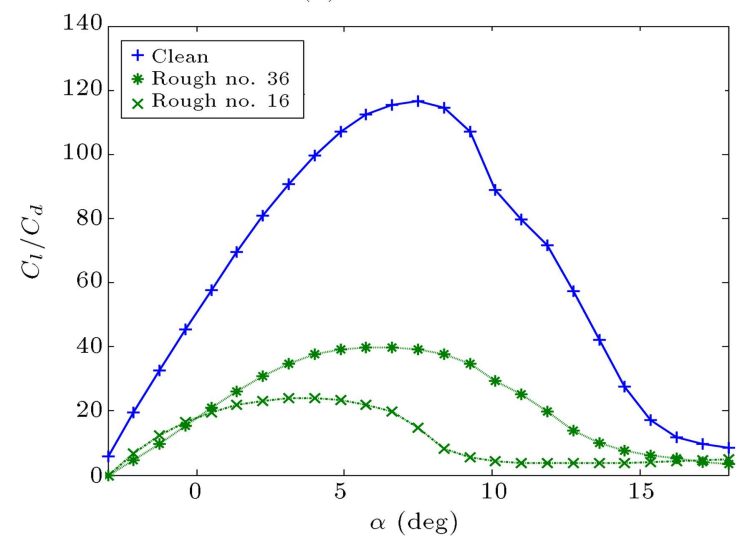

(c) $\operatorname{Re}=1.3 \times 10^{6}$

Figure 10. Effect of roughness on the $C_{l} / C_{d}$ curve.

inspection that roughness leads to a sharp reduction in the maximum value of $\frac{\mathcal{C}_{l}}{\mathcal{C}_{d}}$ for all Reynolds numbers tested (Figure 10). For example, maximum $\frac{\mathcal{C}_{l}}{\mathcal{C}_{d}}$ at $\operatorname{Re}=1.3 \times 10^{6}$ is about 120 for the clean model, while it is reduced to 40 for roughness Nos. of 36,25 , and 16 roughness for the same Reynolds number seen in Figure 10(c). For maximum power production, the lift-drag ratio should be high for airfoils. From these curves, it is seen that surface roughness reduces the maximum power generated by the wind turbine.

Figure 11 shows the effect of different roughness sizes on the total pressure in the wake. measured by the rake far from the model's trailing edge. The roughness expands the wake region both laterally and longitudinally, hence increasing the profile coefficient drag significantly. Similar trends are seen for other Reynolds numbers too, but the data is not present in this paper. Roughness eliminates the transition point on the upper surface by making the flow fully turbulent at all Reynolds numbers.

\subsection{Effect of free-stream turbulent intensity}

The effect of turbulence intensity was investigated at two Reynolds numbers: $\operatorname{Re}=0.43 \times 10^{6}$ and $\operatorname{Re}=0.85 \times 10^{6}$. Figure 12 compares the curve lift coefficient for high turbulence intensity flow generated by inserting a grid in front of the test section. The effect of turbulence intensity at $\operatorname{Re}=0.85 \times 10^{6}$ is more than that in the $\operatorname{Re}=0.43 \times 10^{6}$ case, as seen from Figure 12. Increasing the free-stream turbulence intensity results in the delay of stall, increases the maximum lift coefficient and improves the smoothness of the stall behavior. Moreover, turbulence intensity at a Reynolds number of $\operatorname{Re}=0.85 \times 10^{6}$, increases maximum $\mathcal{C}_{l}$ about $10 \%$.

Figure 13 shows the effect of turbulence intensity on the drag coefficient at two Reynolds numbers. In contrast to the lift coefficient, the $\mathcal{C}_{d}$ behavior with increasing turbulence intensity is different. Increasing turbulence intensity increases the drag coefficient at all angles of attack tested here. Turbulence intensity increases drag coefficient before stall, about $280 \%$ at $\operatorname{Re}=0.43 \times 10^{6}$ and $350 \%$ at $\operatorname{Re}=0.85 \times 10^{6}$. However, variations of $\mathcal{C}_{d}$ with angle of attack for both cases are similar.

Figure 14 shows the effect of turbulence on the $\frac{\mathcal{C}_{l}}{\mathcal{C}_{d}}$ versus angle of attack for two Reynolds numbers. This figure shows that maximum $\frac{\mathcal{C}_{l}}{\mathcal{C}_{d}}$ reaches 75 and 100 at $\operatorname{Re}=0.43 \times 10^{6}$ and $0.85 \times 10^{6}$, respectively, but increasing the turbulence leads to $80 \%$ reduction in this value for both Reynolds numbers. For example, maximum $\frac{\mathcal{C}_{l}}{\mathcal{C}_{d}}$ at $\operatorname{Re}=0.85 \times 10^{6}$ is reduced to 20 due to increasing the turbulence level inside the test section. Further, note that by increasing the turbulence level, the $\frac{\mathcal{C}_{l}}{\mathcal{C}_{d}}$ for both free stream Reynolds numbers are almost identical, while their values are different.

Increasing the turbulence intensity does not affect $\mathcal{C}_{p}$ variation at low angles of attack significantly (Figures 15 and 16). Turbulence eliminates the transition point on the upper and lower surfaces; hence the laminar flow region on the airfoil surface is eliminated. At high angles of attack, however, turbulence seems to have favorable effects on $\mathcal{C}_{p}$ distribution (Figures 15 and 16). Further, it is seen that at low to moderate angles of attack, increasing the tunnel turbulence seems to have an unfavorable effect on the upper surface $\mathcal{C}_{p}$ distribution (Figures 15 and 16). These effects are more 


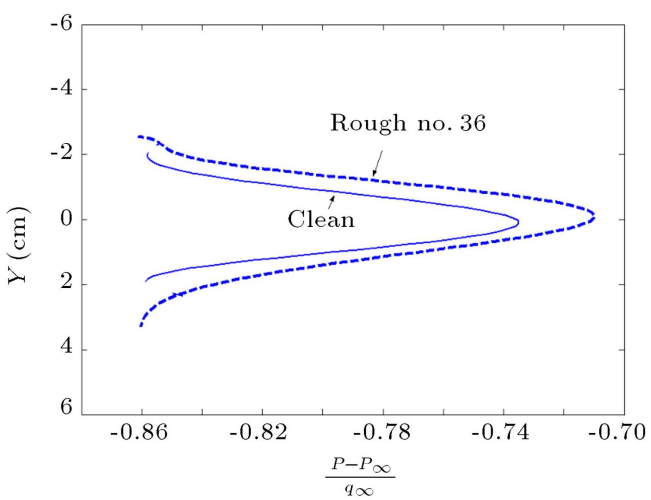

(a) $\mathrm{AOA}=7^{\circ}$

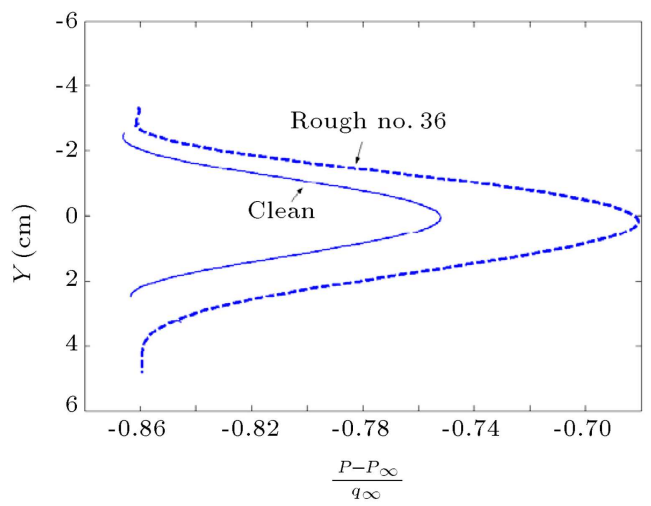

(b) $\mathrm{AOA}=7^{\circ}$

Figure 11. Effect of roughness sizes on the wake at $\operatorname{Re}=0.85 \times 10^{6}$.

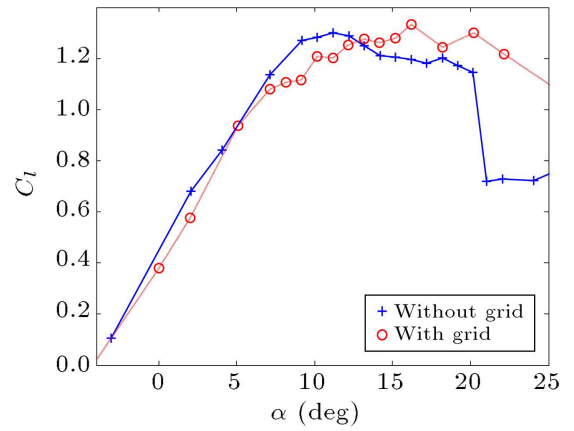

(a) $\operatorname{Re}=0.43 \times 10^{6}$

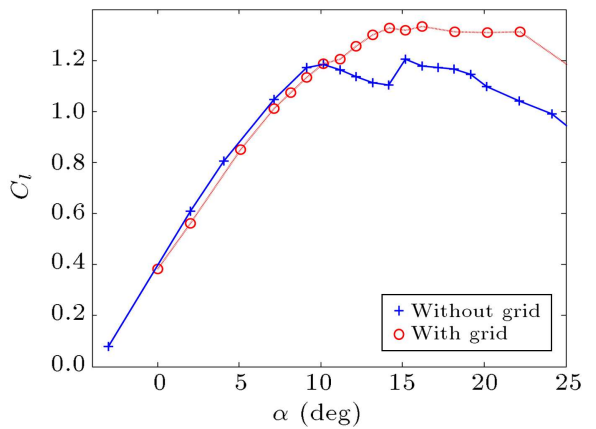

(b) $\operatorname{Re}=0.85 \times 10^{6}$

Figure 12. Effect of freestream turbulence on the $C_{l}$ variations.

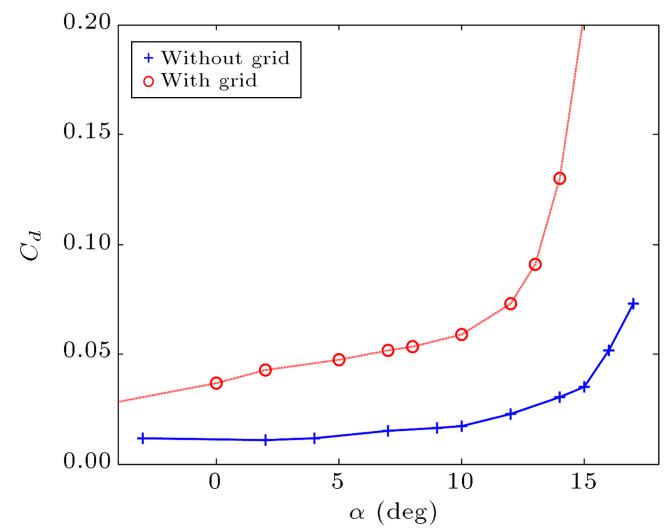

(a) $\operatorname{Re}=0.43 \times 10^{6}$

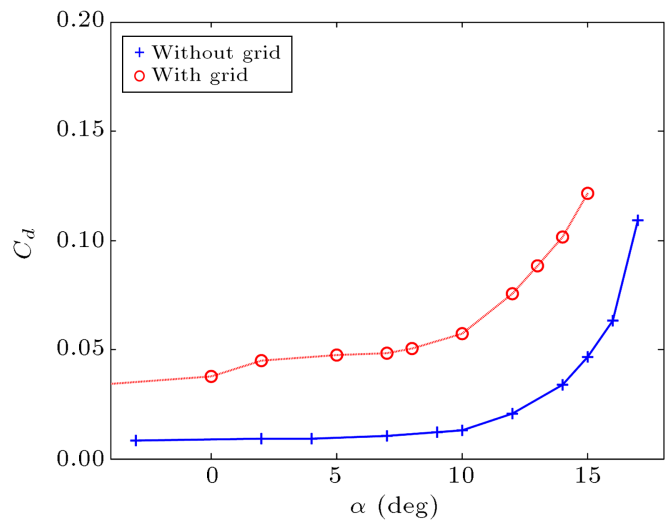

(b) $\operatorname{Re}=0.85 \times 10^{6}$

Figure 13. Effect of freestream turbulence on the $C_{d}$ variations.

pronounced at lower free stream Reynolds numbers, as seen in these figures. However, as the angle of attack increases, $\alpha \geq 16^{\circ}$, the effect is reversed and the $\left|\mathcal{C}_{p}\right|$ data for the high turbulence case are seen to be more than those of low turbulence.

\subsection{Effects on unsteady coefficients}

As mentioned before, unsteady results are obtained by performing sinusoidal oscillation of the model about its quarter chord. The amplitude and mean angles of attack were selected in such a way that during one oscillation cycle, the model could oscillate, below static stall angles of attack, near static stall, or beyond the static stall angle of attack. So, the effects of TI on various unsteady parameters (like reduced frequency, amplitude of oscillation, and mean angle of attack) can be studied [6].

Figure 17 shows several normal force coefficients versus angle of attack for four different mean angle of attacks (in the figure static data is present for comparison) with a reduced frequency of $k=0.07$ for high and low free stream turbulent cases. For 


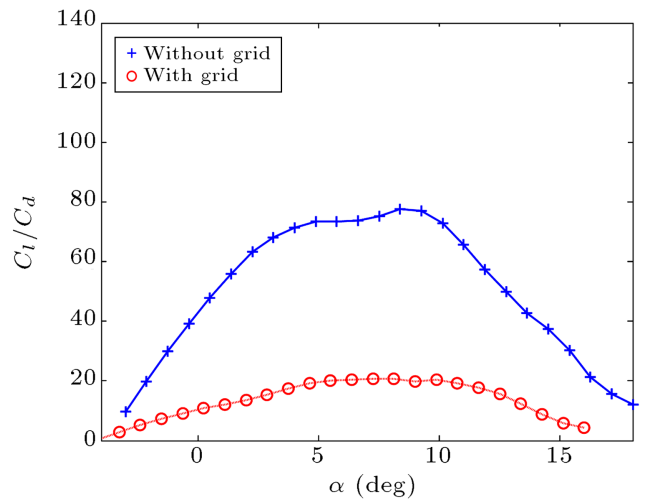

(a) $\operatorname{Re}=0.43 \times 10^{6}$

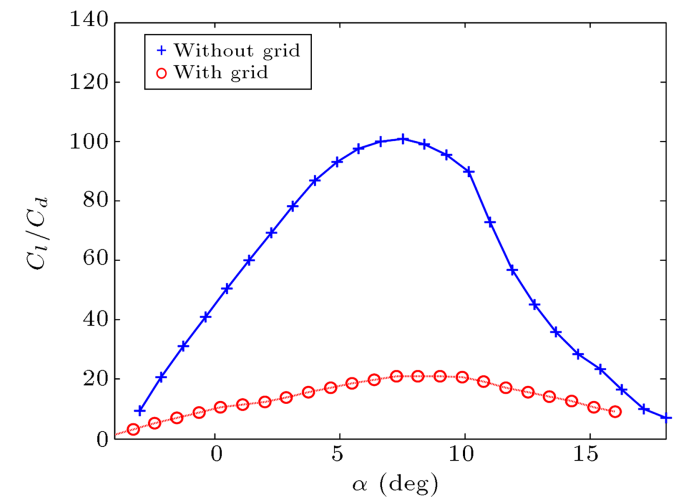

(b) $\operatorname{Re}=0.85 \times 10^{6}$

Figure 14. Effect of freestream turbulence on the $C_{l} / C_{d}$ variations.

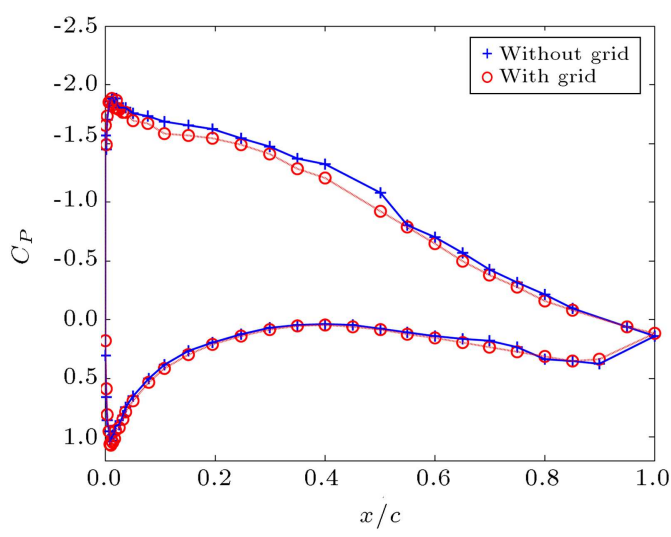

(a) $\mathrm{AOA}=7^{\circ}$

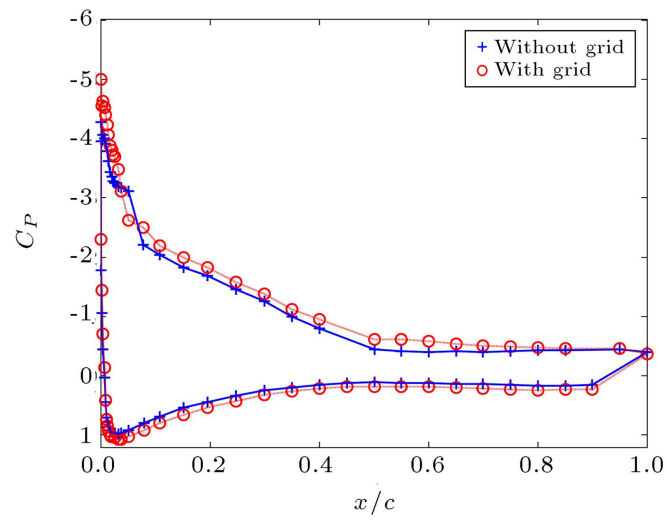

(c) $\mathrm{AOA}=16^{\circ}$

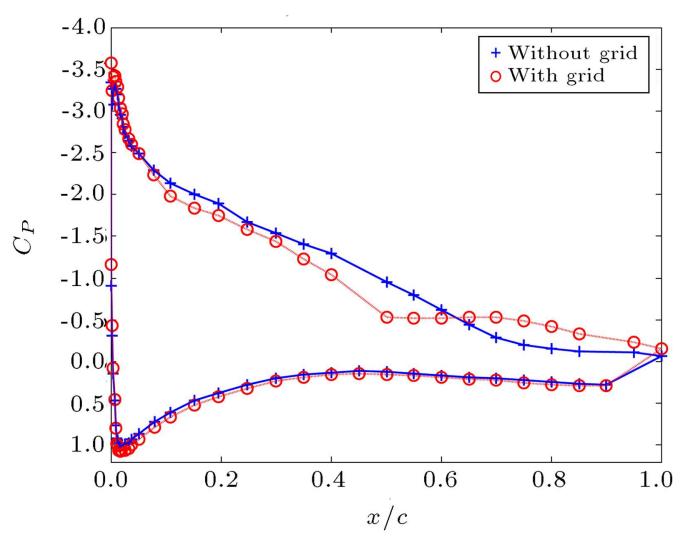

(b) $\mathrm{AOA}=12^{\circ}$

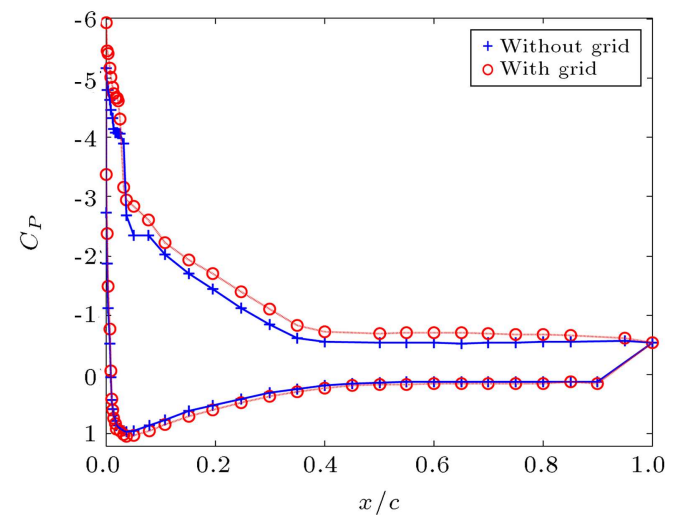

(d) $\mathrm{AOA}=20^{\circ}$

Figure 15. Effect of freestream turbulence on the $C_{p}$ distribution at $\operatorname{Re}=0.43 \times 10^{6}$.

$\alpha=5+2 \sin (\omega t)$, it can be seen that when the model is oscillated below the static stall angel of attack, for both high and low turbulence intensity, in the upstroke motion (increase of the angle of attack) the dynamic values are lower than their static ones. On the other hand, for the downstroke motion (decrease of the angle of attack) his model is oscillated above the static stall angle of attack which is opposed to the upstroke motion. Moreover, increasing the free stream turbulence has a small effect on the $C_{n}$ value and it is more profound for the downstroke case. For the mean angle of attack $\alpha=8+2 \sin (\omega t)$, the model is oscillated near its static stall angle (the static stall angle attack for this airfoil is about $\alpha \simeq 10$ degrees) and Figure 17 shows that static value of $C_{n}$ lags in the upstroke and lead during the downstroke part of the motion. However, for this case increasing the freestream turbulence intensity, influences $C_{n}$ data for all angle of attack when the model is oscillated around its static stall angle. For the $\alpha=10+2 \sin (\omega t)$, the width of the corresponding hysteresis loop is reduced significantly in comparison with the previous two cases. 


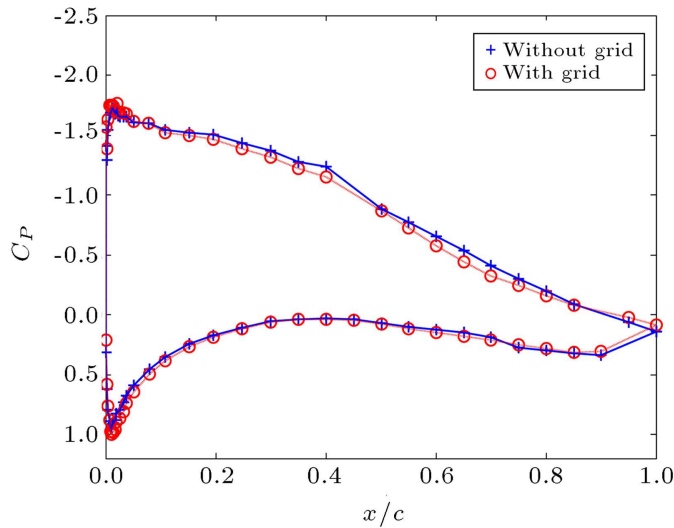

(a) $\mathrm{AOA}=7^{\circ}$

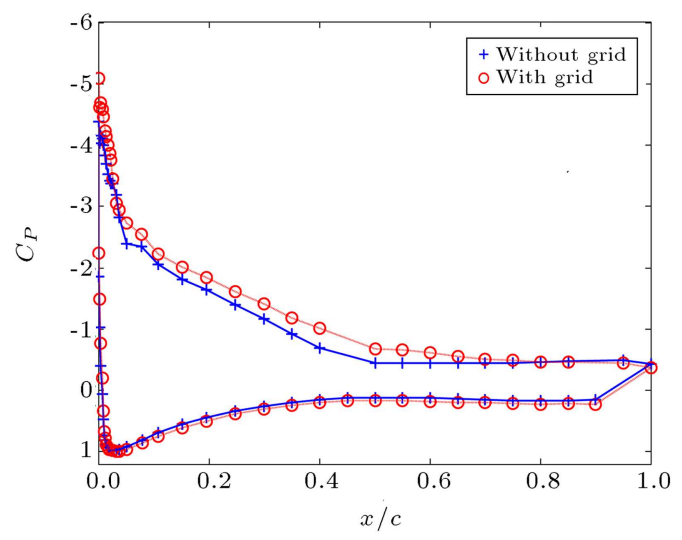

(c) $\mathrm{AOA}=16^{\circ}$

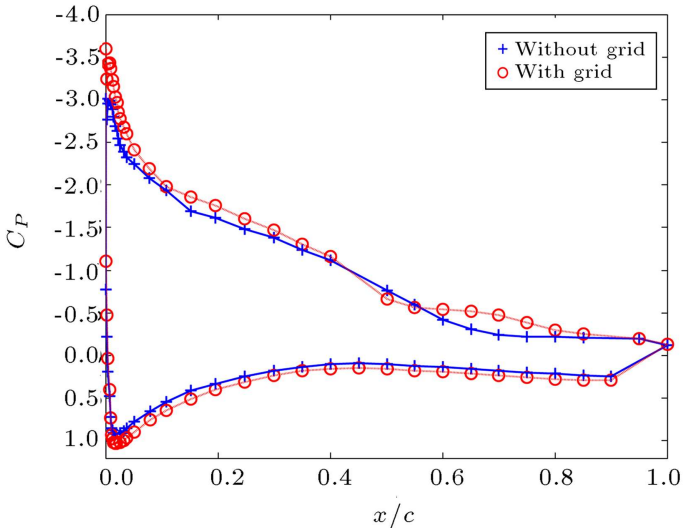

(b) $\mathrm{AOA}=12^{\circ}$

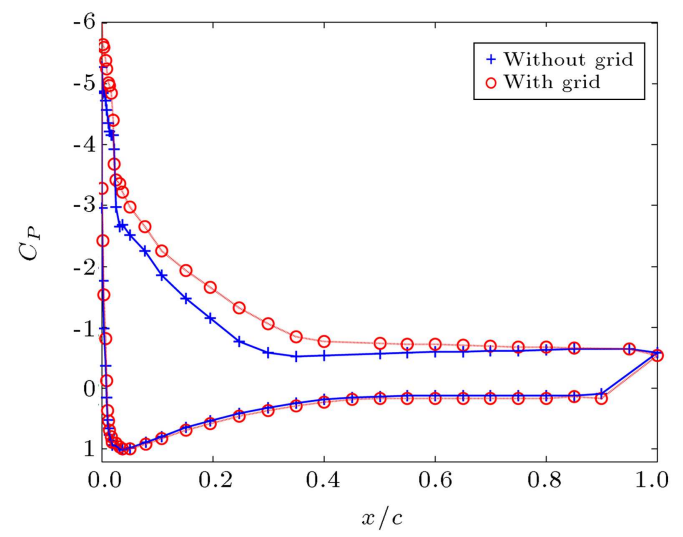

(d) $\mathrm{AOA}=20^{\circ}$

Figure 16. Effect of freestream turbulence on the $C_{p}$ distribution at $\operatorname{Re}=0.85 \times 10^{6}$.

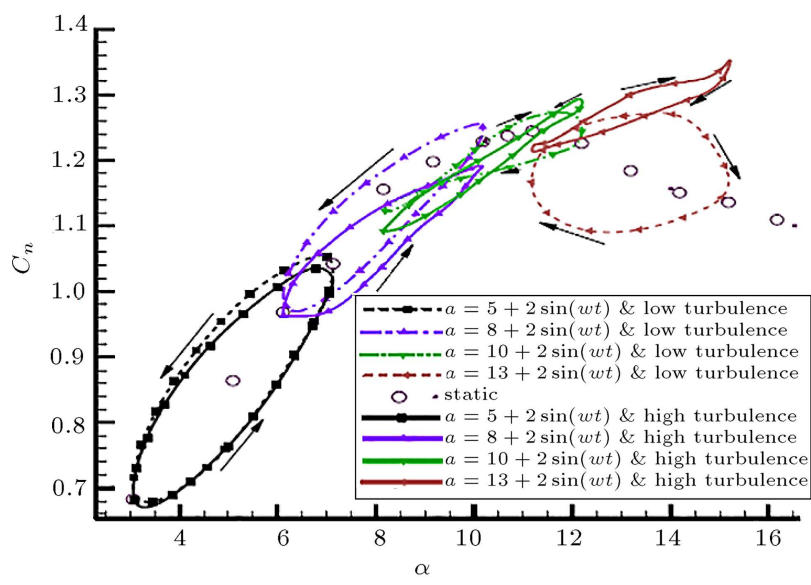

Figure 17. Effect of the freestream turbulence on the normal force coefficient, $\operatorname{Re}=0.43 \times 10^{6}$.

Moreover, dynamic $\mathcal{C}_{n}$ data lead its static value in the upstroke portion of the motion and lags in the downstroke one. Effect of free-stream turbulence on the $\mathcal{C}_{n}$ data is similar to those of the previous cases. Finally for the last mean angle of attack case, $\alpha=$ $13+2 \sin (\omega t)$, it is seen that dynamic $\mathcal{C}_{n}$ data leads and lags its corresponding static values for the upstroke and downstroke portion of the motion respectively. In addition, even for this low reduced frequency case, there is no sign of stall for the dynamic $\mathcal{C}_{n}$ data for the low turbulence case. In other hands, dynamic data for the high turbulence case has a different behavior. The hysteresis loop of the $C_{n}$ data is much wider than that of similar cases, but lower for TI cases Figure 17 while the value of $C_{n}$ for all angles of attack are much lower. From these data, it could be concluded that turbulence intensity has a significant effect on the $C_{n}$ data at high angles of attack.

\subsection{Effect of surface roughness}

To study the effect of surface roughness on the pressure variation of the airfoil, standard commercial grit number of 26 was used. Surface roughness was applied at two different locations of the upper surface, $\frac{x}{c}=$ 0.05 and $\frac{x}{c}=0.35$, using a $12 \mathrm{~mm}$ double-stick tape along the airfoil span. The model was set to a mean angle of attack of 10 degrees and the chord Reynolds number was $0.63 \times 10^{6}$. In the plunging motion, the model was oscillated with a plunging amplitude of $h= \pm 10 \mathrm{~cm}$ and at different frequencies. Figures 18 and 19 depict the effect of the surface roughness on the airfoil pressure variations for both motions. The pressure hysteresis loops of the clean model and the one with the roughness are plotted for a reduced frequency of $k=0.07$. These figures show both motions when 

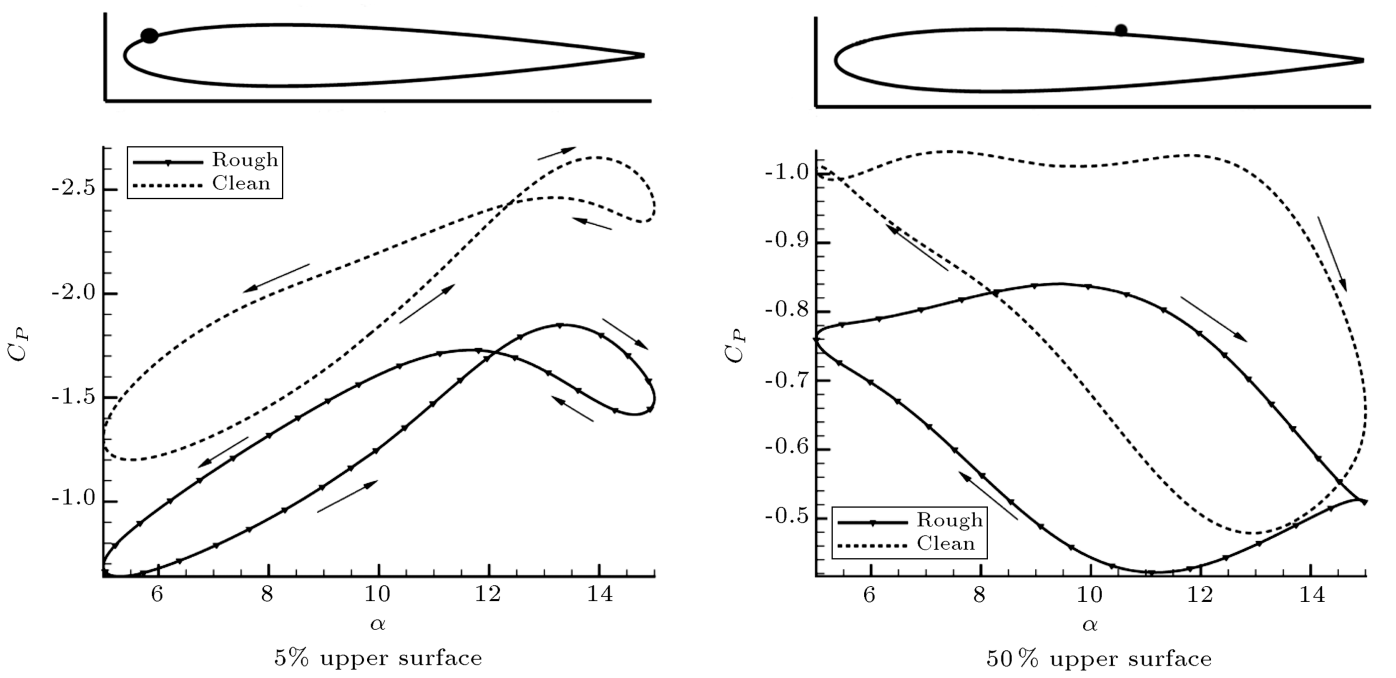

(a) Roughness at 5\% upper surface
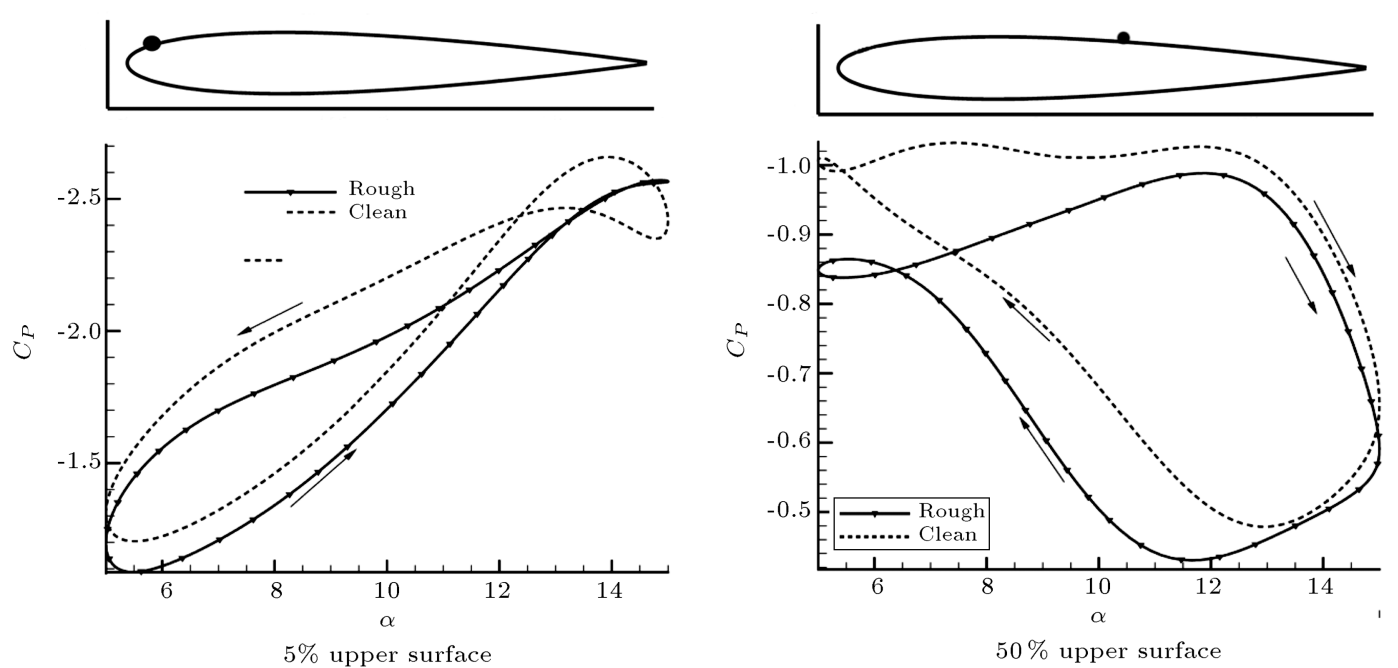

(b) Roughness at $35 \%$ upper surface

Figure 18. Effect of roughness on the pressure coefficients in the pitching motion, $k=0.07$.

the roughness is applied near the leading edge. A decrease in both $\mathcal{C}_{P}$ and the width of the hysteresis loops can be observed (Figures 18 and 19). The reason for this phenomenon is probably due to the turbulent flow that decreases the flow unsteadiness. Furthermore, it is seen from these figures that the roughness effects on the $C_{P}$ variations are more pronounced when they are applied near the leading edge, $\frac{x}{c}=5 \%$, than at $\frac{x}{c}=35 \%$.

Further, its effect on the pressure-gradient-lag is the same for both types of motion. The pressure response actually has contributions from both angles of attack and pitch-rate terms. The difference between the two types of motion is due to the presence of the pitch rate in the pitching oscillation, which is absent in the plunging case.

Therefore, it could be concluded that increasing oscillation amplitude is more effective for the plunging motion than for the pitching one, because pitch rate in the pitching motion prevents flow separation.

\subsection{Effects on predicted output power}

A computer program based on the BEM method [12] was developed to predict the power output of a blade. The program required aerodynamic coefficients of the airfoils, which were used throughout the blade. This experiment has been done for only a critical section of the wind turbine blade, therefore the airfoil data used in this wind turbine are not known. However, with current experimental results and using Eppler and XFOIL codes $[18,19]$, the codes calibrate based on the experimental data, and then with using these codes the aerodynamic coefficients of the airfoil are calculated and used in BEM code. It is interesting to note that TI has quite different effects on the output power of the blade for operational conditions with Free Stream 

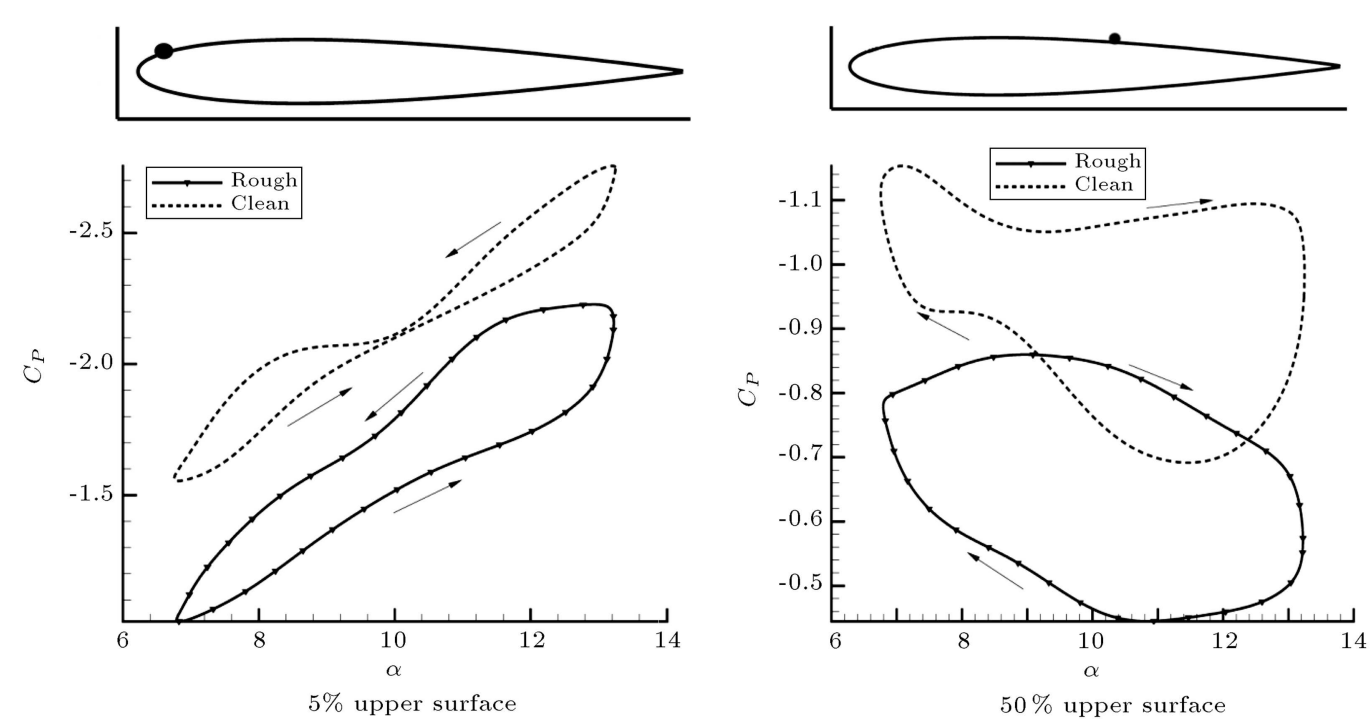

(a) Roughness at 5\% upper surface
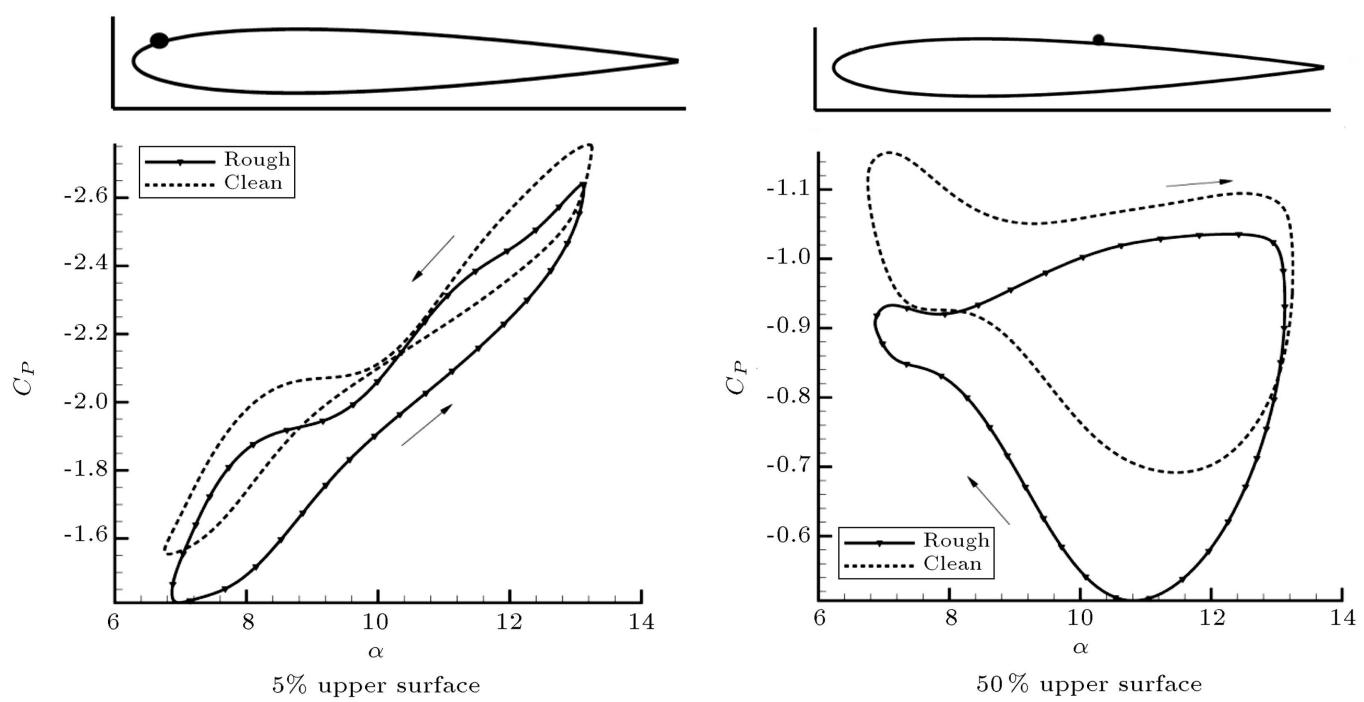

(b) Roughness at $35 \%$ upper surface

Figure 19. Effect of roughness on the pressure coefficients in plunging motion, $k=0.07$.

Velocity (FSV) below or higher than $10 \frac{\mathrm{m}}{\mathrm{s}}$. At the region with free stream velocity lower than $10 \frac{\mathrm{m}}{\mathrm{s}}$, the power was improved. In the other hand, this effect was reversed for free stream velocity higher than $10 \mathrm{~m} / \mathrm{s}$, as seen in Figure 20.

\section{Conclusion}

Extensive wind tunnel tests have been conducted to investigate the effect of free stream turbulence intensity on both steady and unsteady aerodynamic performances of a section of a $660 \mathrm{kw}$ wind turbine blade. The tests included study of roughness and turbulence effects at different Reynolds numbers, and interesting results were obtained when the grid was installed upstream of the test section of the wind tunnel to increase turbulence intensity. Increasing the turbulence intensity resulted in a delay in stall, increase of maximum lift coefficient, and the smoothness of stall behavior. Despite the favorable effect of turbulence on the lift coefficient, it has unfavorable effects on the drag coefficient of the airfoil. The results show that roughness reduces the section aerodynamic efficiency and lift coefficient, and increases the drag coefficient for all Reynolds numbers tested. In addition, a computer program has been developed to study the effects of this parameter on the predicted output power of the blade.

Applying the surface roughness near the leading edge affects the performance of the airfoil significantly and results in the reduction of both $C_{P}$ and width of the hysteresis loops. Its effect is more pronounced when it is applied at $\frac{x}{c}=5 \%$ for both types of motion.

Furthermore, turbulence intensity depicts quite different effects on the predicted output power if it 


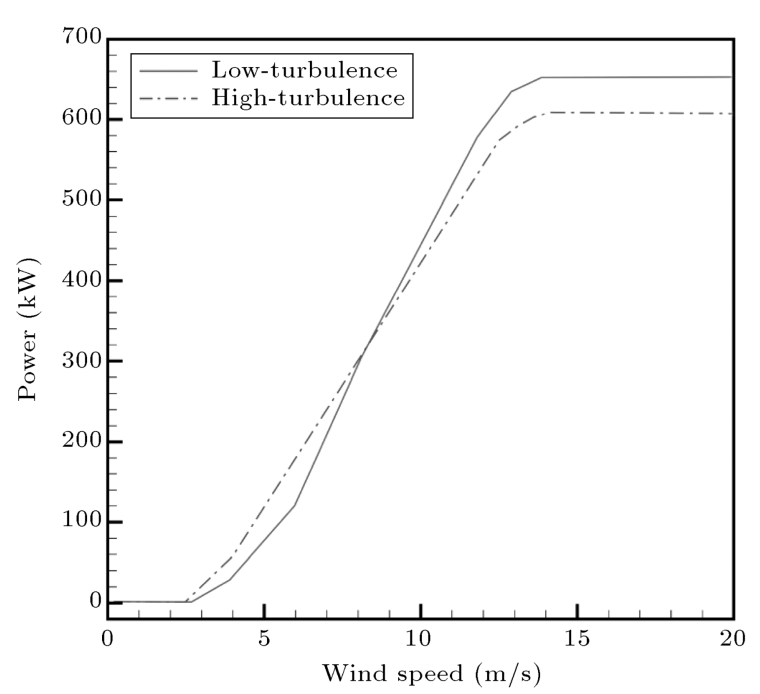

Figure 20. Prediction of the effects of turbulence on output power of the wind turbine at different velocities using BEM method.

works at low or high free stream velocities. Whereas it improves the output power for a region with low Reynolds numbers, it has a reverse effect at the high Reynolds number one. However, since the wind turbine blades operate at free stream velocities around $15 \mathrm{~m} / \mathrm{s}$, it can be concluded that TI should be as low as possible to obtain a better performance.

\section{Nomenclature}

$\begin{array}{ll}\text { HAWT } & \text { Horizontal Axis Wind Turbine } \\ U_{\infty} & \text { Free stream velocity }(\mathrm{m} / \mathrm{s}) \\ c & \text { Airfoil chord }(\mathrm{m}) \\ C_{P} & \text { Pressure coefficient } \\ C_{l} & \text { Lift force coefficient } \\ C_{d} & \text { Drag force coefficient } \\ C_{m} & \text { Pitching moment coefficient about } c / 4 \\ h & \text { Plunging displacement }(\mathrm{cm}) \\ k & \text { Reduced frequency, } K=\frac{\pi+f}{U_{\infty}} \\ \alpha & \text { Angle of attack (deg) } \\ \bar{\alpha} & \text { Amplitude of the pitching motion } \\ & \text { (deg) } \\ f & \text { Oscillation frequency }(\mathrm{Hz}) \\ \text { AOA } & \text { Angle Of Attack } \\ \text { BEM } & \text { Blade Element Momentum } \\ \text { TI } & \text { Turbulent Intensity }\end{array}$

\section{References}

1. Timmer, W. and Schaffarczyk, A. "The effect of roughness at high Reynolds numbers on the performance of aerofoil DU 97-W-300Mod", Wind Energy, 7(4), pp. 295-307 (2004).
2. Bak, C., Fuglsang, P. and Sørensen, N. "Airfoil characteristics for wind turbines", Ris $\varnothing$-R-1065(EN) Ris $\varnothing$ National Laboratory, Roskilde (1999).

3. Lubitz, W.D. "Impact of ambient turbulence on performance of a small wind turbine", Renewable Energy, 61, pp. 69-73 (2014).

4. Swalwell, K., Sheridan, J. and Melbourne, W. "The effect of turbulence intensity on performance of a NACA 4421 airfoil section", 42nd AIAA Aerospace Sciences Meeting and Exibit (2004).

5. Luhur, M., Peinke, J., Schneemann, J. and Wächter, M. "Stochastic modeling of lift and drag dynamics under turbulent wind inflow conditions" , Wind Energy, 18(2), pp. 317-337 (2015).

6. Soltani, M.R., Bakhshalipour, A. and Seddighi, M. "Effect of amplitude and mean angle of attack on the unsteady surface pressure of a pitching airfoil", Journal of Aerospace Science and Technology, 2(4), pp. 9-26 (2005).

7. Soltani, M.R., Seddighi, M. and Marzabadi, F.R. "Comparison of pitching and plunging effects on the surface pressure variation of a wind turbine blade section", Wind Energy, 12(3), pp. 213-239 (2009).

8. Seddighi, M. and Soltani, M.R. "Effect of surface roughness on an airfoil in pitching motion", 36th AIAA Fluid Dynamics Conference and Exhibit., San Francisco, California (2006).

9. Højstrup, J. "Spectral coherence in wind turbine wakes", Journal of Wind Engineering and Industrial Aerodynamics, 80(1-2) pp. 137-146 (1999). Doi:10.1016/S0167-6105(98)00198-6.

10. Högtröm, U., Asimakopoulos, D.N., Kambezidis, H., Helmist, C.G. and Smedman, A. "A study field of the wake behind a $2 \mathrm{MW}$ wind turbine", Atmospheric Environment, 22(4), pp. 803-820 (1988).

11. Mccroskey, W.J. "Unsteady airfoils", Annual Review of Fluid Mechanics, 14, pp. 285-311 (1982).

12. Øye, S. "Dynamic stall - simulated as time lag of separation", Proceedings of the 4th IEA Symposium on the Aerodynamics of Wind Turbines (1991).

13. Hansen, A.C. and Butterfield, C.P. "Aerodynamics of horizontal-axis wind turbines", Annual Review of Fluid Mechanics, 25, pp. 115-149 (1993).

14. Ingram, G., Wind Turbine Blade Analysis Using the Blade Element Momentum Method, version 1.0, School of Engineering, Durham University, UK (2005).

15. Barlow, J.B., Rae, W.H. and Pope, A., Low-Speed Wind Tunnel Testing, 3rd Ed., John Wiley \& Sons (1999).

16. Carta, F. "A comparison of the pitching and plunging response of an oscillating airfoil", National Aeronautics and Space Administration, Scientific and Technical Information Branch, (1979).

17. Soltani, M.R. and Bakhshalipour, A. "Effect of amplitude and mean angle-of-attack on the boundary layer of an oscillating aerofoil", Aeronautical Journal, 112(1138), p. 705 (2008). 
18. Eppler, R. and Somers, D.M. "Supplement to: A computer program for the design and analysis of low-speed airfoils", National Aeronautics and Space Administration, Scientific and Technical Information Branch (1980).

19. Drela, M. "XFOIL: An analysis and design system for low Reynolds number airfoils", Low Reynolds Number Aerodynamics, 54, pp. 1-12 (1989).

\section{Biographies}

Mohammad Reza Soltani has a $\mathrm{PhD}$ degree in Aerodynamics from the University of Illinois at Urbana-Champaign, USA, and is currently Professor in the Aerospace Engineering Department of Sharif University of Technology, Tehran, Iran. His research interests include applied aerodynamics, unsteady aerodynamics wind tunnel testing, wind tunnel design, and data processing.

Farshid Askari, graduated with a BS degree in Aerospace Engineering from Sharif University of Technology, from where he also received his MS in Aerodynamics. His research interests include applied aerodynamics, unsteady aerodynamics wind tunnel testing, and data processing.

Vahid Sadri is currently a $\mathrm{PhD}$ degree candidate in the Mechanical Engineering Department of Southern Methodist University, USA. His research interests include vortex dynamics, vortex rings, unsteady aerodynamics, wind tunnel testing, and data processing. 